\title{
Articles
}

\section{Plurilingual Students' Practices in a Canadian University: Chinese Language, Academic English, and Discursive Ambivalence}

\author{
Steve Marshall, Danièle Moore, Connie Lam James, \\ Xiaojie Ning, \& Pedro dos Santos
}

We present findings from a 1-year study of students' plurilingualism across the disciplines in Canadian higher education. We analyze how students exercise their plurilingual competence, focusing on the use of Chinese languages as tools for learning at a university in Metro Vancouver, Canada. The following data are presented: field notes taken during classroom observations, transcripts of recordings of students using Chinese languages while working collaboratively, and semistructured interviews with students in which they discuss how they use languages for learning. We weigh the creative and instrumental use of Chinese languages as tools for learning against the dominance of academic English. We suggest that the tension between the use of Chinese languages during the process of learning and academic English for assessment underlies the ambivalence around which student participants perceive and practice plurilingualism in higher education.

Nous présentons les conclusions d'une étude d'une durée d'un an sur le plurilinguisme estudiantin à travers les disciplines de l'enseignement supérieur canadien. Nous analysons la façon dont les étudiantes et étudiants exercent leur compétence plurilingue en nous concentrant sur l'utilisation de langues chinoises comme instruments d'apprentissage dans une université du district régional du Grand Vancouver au Canada. Les données suivantes sont présentées : notes prises lors d'observations en classe, transcriptions d'enregistrements d'étudiantes et étudiants communiquant en langues chinoises dans le cadre de travaux en collaboration, et entrevues semi-structurées au cours desquelles ils discutent de la façon dont ils utilisent les langues pour apprendre. Nous établissons une pondération entre l'utilisation créative et instrumentale des langues chinoises comme outils d'apprentissage et la domination de l'anglais académique. Nous suggérons que la tension qui existe entre l'utilisation des langues chinoises en cours d'apprentissage et l'utilisation de l'anglais académique pour l'évaluation souligne l'ambivalence dans laquelle baignent les perceptions et les pratiques plurilingues des étudiantes et étudiants de langues chinoises au niveau de l'enseignement supérieur.

KEYWORDS: plurilingualism, higher education

TESL CANADA JOURNAL/REVUE TESL DU CANADA

VOLUME 36, ISSUE 1, 2019 PP. 1-20

https://doi.org/10.18806/tesl.v36i1.1300 


\section{Introduction}

There have been a large number of works in recent years on the topic of plurilingualism in different social, professional, and educational contexts. Many of these have focused on theoretical understandings of plurilingualism and plurilingual competence, from Coste, Moore, and Zarate $(1997,2009)$ to Council of Europe (2018), and plurilingualism in K-12 educational contexts in Europe (e.g., Moore \& Castellotti, 2008). A smaller number of works have analyzed plurilingualism and plurilingual pedagogical approaches in higher education contexts (e.g., Berthoud, Grin, \& Lüdi, 2013), with some recent studies looking specifically at plurilingualism in higher education institutions in Canada (Chen, 2018; Corcoran, Gagné, \& McIntosh, 2018; Englander \& Corcoran, 2019; Galante, 2018, 2019; Marshall \& Moore, 2013, 2018; Lau \& Van Viegen, forthcoming; Van Viegen \& Zappa-Hollman, forthcoming). The aim of this article is to build upon the growing number of Canada-based studies on plurilingualism in higher education by focusing on the practices and perceptions of plurilingual students who are studying in linguistically diverse classes across the disciplines: how they use language in and around their learning, their attitudes about language use, and the pedagogical implications of these practices.

We present selected data from a 1-year ethnographic study of plurilingualism as an asset for learning across the disciplines in Canadian higher education conducted between 2016 and 2017. We begin by presenting data from an undergraduate linguistics class at a university in Metro Vancouver, Canada, in which students used Mandarin as part of the process of learning course content. We then analyze data from an undergraduate comparative literature class in which plurilingualism-inspired pedagogical approaches were proactively integrated into the course to promote language awareness and enrich the learning of course content. Next, we present data from interviews in which student participants from the two classes described their plurilingual practices at the university, before considering the implications for higher education in Canada.

Data were collected at a university we call Western Metropolitan University (WMU), located in Metro Vancouver, Canada, an urban area with a population of approximately 2.5 million. In the 2016 Census, 1,020,250 $(41.8 \%)$ respondents reported speaking a mother tongue other than English or French, the two official languages of Canada. Among the immigrant languages, Chinese languages were reported to be the family languages of $45 \%$ of Census respondents (Mandarin 22\%, Cantonese 21\%, Chinese languages-other $2 \%)$, Punjabi (17\%), Korean (6\%), Tagalog (5\%), Farsi $(4 \%)$, Spanish (3\%), and Vietnamese (2\%) (Statistics Canada, 2016). Another important factor that relates to how languages are used in individuals' lives is the diasporic settlement of different immigrant communities in the different municipalities of Metro Vancouver, where, in certain parts of the city, more 
than $85 \%$ of the population speak immigrant languages at home, with high concentrations of single languages in several areas (Statistics Canada, 2011). As a result, it is common to hear different languages being spoken by many people as they go about their daily lives in the city's shopping malls, schools, colleges, and universities, and on its buses and trains.

In the corridors and classes of WMU, plurilingual students frequently use languages other than English in general conversations with other students and as they engage with academic content in different courses across the disciplines. Despite the plurilingual nature of many students' practices, the university can be described as an institution where, in many respects, deficit views of multi/plurilingual students prevail, a result perhaps of institutional discourses that view plurilingualism through monolingual(ist) lenses. Students, therefore, need to be able to employ complex strategies about how, when, and where to use languages other than English according to their established relationships with other speakers as well as their understandings of institutional discourses (often characterized by ambivalence) about what is normal and acceptable in different locations. The questions we ask, therefore, are the following:

- How and why do plurilingual university students use languages other than English in the process of learning course content?

- Can the use of languages other than English enrich learning?

- What are the pedagogical implications of encouraging students to engage in plurilingual practices in different disciplinary contexts?

\section{Students' Plurilingualism ${ }^{1}$ in Higher Education}

Plurilingual students' interactions in higher education contexts can be understood as those "involving multiple languages, in which interlocutors may switch and mix languages purposefully and/or creatively without necessarily being completely fluent in one or all of the languages involved" (Marshall, 2019 , in press). The way in which a plurilingual speaker may make use of his or her linguistic repertoires always depends on context, in other words, how the socially situated actor (Moore \& Gajo, 2009) chooses to use languages (or not) according to social/educational/cultural trajectories, opportunities, and constraints in different contexts (Coste, Moore, \& Zarate, 1997, 2009; Lüdi \& Py, 2009).

In the contexts of higher education, plurilingual students may make use of their linguistic and cultural repertoires in classrooms where, in few cases, their instructors may have proactively incorporated plurilingual teaching approaches; in others, most likely the majority of cases, instructors will develop their pedagogies reactively as they decide how to respond to linguistically 
diverse classes. Plurilingualism-inspired pedagogy may come in many forms, and can be characterized by the following features: the creation of synergies between languages as part of reaching a higher goal; the raising of awareness and increasing self-esteem of learners in ways that will optimize learning, increased agency, and self-efficacy; and challenges to traditional diglossic, compartmentalizing views of language in classrooms (Piccardo, 2013). Accordingly, students' languages are seen as assets for learning rather than a hindrance or problem to be fixed (Lin, 2013; Marshall \& Moore, 2018).

For a plurilingualism-inspired classroom to succeed across the disciplines in higher education, both teachers and students need to exercise their socially situated agency to open up spaces for other languages and cultures to be used successfully in the learning process. This can be a challenge for students as well as their instructors. For example, plurilingual approaches may confuse students who may have been conditioned in other learning contexts to use English only in classes; such approaches can also be a challenge for instructors who may tend to rely on traditional pedagogical practices and who often lack any form of training that relates to applied linguistics (Canagarajah \& Liyanage, 2012; Piccardo, 2013).

Another factor that is key to effective teaching and learning in linguistically diverse higher education classes is plurilingual and pluri/intercultural mediation (Council of Europe, 2018; Liddicoat, 2014; Piccardo, 2012; Zarate, 2004), which can involve instructors, teaching assistants, and students acting as mediators where gaps in the comprehension of language and content occur. Such mediation can facilitate direct communication between individuals where a language gap exists (Council of Europe 2001, as cited in Piccardo \& North, in press), negotiation of the meaning of a written text, and mediation of the mental processes involved while carrying out specific tasks (Piccardo, 2012).

Recognizing the complex balance between opportunity, constraint, and practice is particularly important when it comes to analyzing plurilingual students' practices, or their agency, within the often rigid structures of higher education. An over-agentive plurilingual focus that might highlight students' potential to exercise their agency (or plurilingual competence) to engender change in the institutional structures of the university is problematic due to students' lack of symbolic and social capital (Bourdieu, 1994) in the academic hierarchy. It may be more likely, perhaps, that students reproduce institutional discourses about plurilingualism in their practices, reflecting a process of structural conditioning (Archer, 2003). As a result, our focus is specifically (but not exclusively) on individuals' language use (Piccardo, 2013) in different disciplinary contexts at WMU.

As mentioned above, students' plurilingual practices in higher education have been the focus of a small number of Canadian studies. Marshall and Moore $(2013,2018)$ found that plurilingual students used Mandarin, Korean, and Punjabi as tools for learning in their first-year academic literacy classes at 
a university in Metro Vancouver, emphasizing the important role of teacher agency in facilitating plurilingual approaches. In Chen's (2018) mixed methods study, the author analyzed the relationship between academic language policy and plurilingual practices at a Canadian university, while Galante $(2018,2019)$ studied students' responses to plurilingualism-inspired classroom activities in the context of Canadian English for academic purposes (EAP) classes. Marshall (in press) analyzes students' plurilingual practices and instructors' pedagogical responses, first in a first-year academic literacy class and then in three contexts across the disciplines at a Vancouver university, stressing the interrelationships between language, content, and context as determining factors in the applicability (or not) of plurilingual teaching approaches in the classes studied. The role of plurilingualism in the thesis writing process of plurilingual scholars at a Canadian university is the focus of Corcoran, Gagné, and McIntosh (2018), while Englander and Corcoran (2019) apply the concept of critical plurilingual pedagogies in their study of English for research publication processes (ERPP). Van Viegen and Zappa-Hollman (forthcoming) analyze the role of plurilingualism-inspired pedagogical approaches at two Western Canadian institutions, with a specific focus on the roles played by instructors in mediating students' plurilingual practices in the classroom.

One thing that all of these studies share is that they took place at institutions where plurilingual students use languages other than English in the learning process while being required to show their knowledge of learning via texts and assignments that are monolingual, requiring advanced skills in academic English. We will suggest that this tension between plurilingual process and monolingual product (assessed in academic English) underlies students' and instructors' sense of ambivalence about plurilingualism in many Canadian higher education contexts.

\section{The Study}

The data presented in this article have been selected from a 1-year study of plurilingualism as an asset for learning across the disciplines in Canadian higher education. Data that related most closely to the research questions stated above were selected. Data for the broader study were collected by a plurilingual research team of two investigators and six research assistants in the university's Faculties of Arts and Applied Sciences, comprising the following: $40 \mathrm{hr}$ of classroom observation with fieldnotes, $5 \mathrm{hr}$ of recordings of students' interactions while they worked on collaborative tasks in their classes, semistructured interviews (lasting between 20 and $40 \mathrm{~min}$ ) with seven instructors and 23 students, and students' writing samples and language portraits drawn during interviews. Research assistants entered classes and were given a space by instructors to show students a study details document in which the study was described. Students were informed that confidentiality 
would be guaranteed by changing the names of individuals, courses, and faculties. Those interested signed consent forms. In this article, the following data are presented: field notes from classroom observations, recordings of students' interactions in class as they carried out collaborative tasks using languages other than English, and excerpts from interviews in which students were asked about their practices and attitudes. Data were coded and analyzed based on emerging themes as well as the research questions framing the study. Interviewers tended to use the term multilingual(ism) rather than plurilingual(ism) as participants were more familiar with the former.

Data from classroom recordings include excerpts from the following participants (courses attended and known languages are included):

- Chris-Comparative Literature-Speaks English, Mandarin, Wu Dialect, Farsi

- Rebecca-Comparative Literature-Speaks English, Cantonese

- Chen-Linguistics-Speaks English, Mandarin

- Yu-Linguistics-Speaks English, Mandarin

Interview excerpts from the following students are analyzed:

- Amber-Comparative Literature-Speaks English, Korean, French, Japanese

- Chris-Comparative Literature-Speaks English, Mandarin, Wu Dialect, Farsi

- Meghan-Comparative Literature-Speaks English, German, French

- Wei-Comparative Literature-Speaks English, Mandarin

- Angel-Linguistics-Speaks English, Mandarin

- Bo-Linguistics-Speaks English, Mandarin

- Chen-Linguistics-Speaks English, Mandarin

- Dahia-Linguistics-Speaks English, Mandarin

- Fen-Linguistics-Speaks English, Mandarin

- Rou-Linguistics-Speaks English, Mandarin

- Shan-Linguistics-Speaks English, Mandarin

- Shui-Linguistics-Speaks English, Mandarin 


\section{Case 1: Using Mandarin in Linguistics 300}

Linguistics 300 was a third-year linguistics class made up of 42 students, among whom roughly one third were Mandarin speakers. The instructor allowed students to use other languages during classes despite feeling reservations that such practices may not help students to pass their summative assignments, which required advanced academic English. One Mandarinspeaking research assistant attended repeated sessions of the classes (approximately $10 \mathrm{hr}$ in total), collecting data as a walking ethnographer (Pink, 2008), engaging with students, taking field notes, recording students' interactions as they worked collaboratively on tasks, and recruiting potential participants for interviews.

A common feature of the class was the use of Mandarin in conversations, discussions, and collaborative group work among those who could speak the language, as the following retrospective field note taken by the research assistant illustrates:

The instructor distributed students a paper which exhibited two interacting phonological rules and she asked students to discuss several questions on this paper within a group. I sat close to one group of Mandarin speakers, two girls and one boy sitting together. I noticed they used Mandarin as a medium to communicate with one another and to figure out the teacher's question.

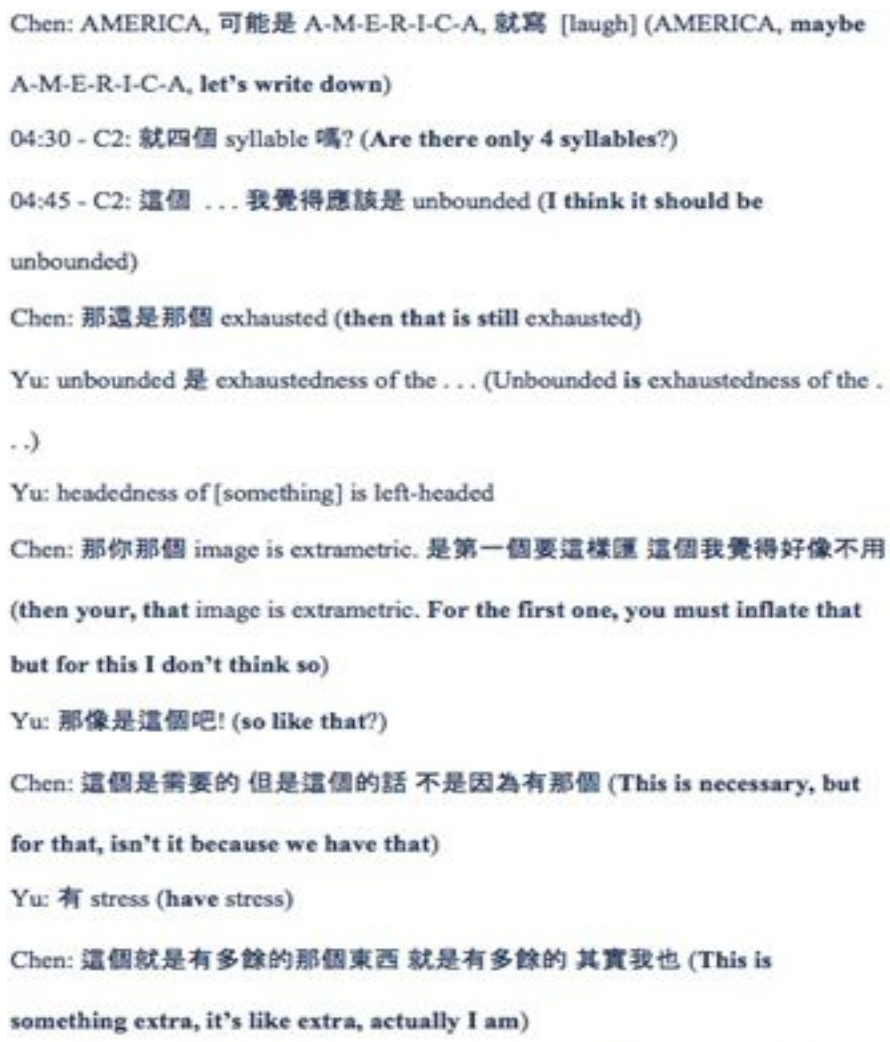

As a Mandarin speaker herself, the research assistant decided to focus on the use of Mandarin in the class, recording interactions with digital voice recorders placed on tables. The transcript to the left of one of the recordings taken during one of the sessions illustrates how students used Mandarin to discuss course content, in this case, a discussion about phonetics:

Figure 1 (on left):

Students' Discussion of

Phonetics. 
In the excerpt above, two students, Chen and $\mathrm{Yu}$, use Mandarin to discuss their understandings of technical terms in the field of phonetics: unbounded, exhausted(ness), headedness, extrametric, and stress. The majority of the content-led discussion is in Mandarin while the technical terms remain in English. In this way, Mandarin is used by the students as the main tool to engage with the course content. The research assistant also arranged interviews in which she asked students why they choose to use Mandarin during classes rather than engaging with the course content in English. The following excerpts show the reasons that interviewees gave:

Angel: It's much easier to use native language to talk about assignments and tasks in the group discussion. In study group, we also use Mandarin to discuss problems. It improves our study.

Bo: Speaking Mandarin with Chinese students in the group discussion can give a sense of closeness, which I think is important for me.

Chen: If we refer to some technical terms, we use English because it is not easy to translate them, but for general questions, we just use Mandarin which is easier for understanding each other.

Fen: In group discussion, if I sit with groups of native speakers, I feel stress and sometimes I can't catch up with them, but if I am in groups of Chinese students speaking Mandarin, I feel comfortable and more confident and it helps my study.

The four excerpts reveal a range of reasons for using Mandarin instead of English in class: ease of communication and understanding, improving studies, a sense of closeness, problems with translation, avoiding stress felt when speaking with native speakers of English, comfort, and confidence. Together, they reflect a key goal of plurilingual pedagogy, that is, to open up spaces for the use of other languages as tools for learning. Clearly, the recording of the interaction above and the interview excerpts would suggest that other languages, Mandarin in this case, can be used successfully to engage with course content and enrich learning. Nonetheless, a major tension in employing such approaches remains. While the process of engaging with course content in class may be enhanced by using languages other than English, students' summative assessments (examinations, tests, presentations, and written assignments) will be in English and will require high levels of competence in academic English to pass the course. We will return to this point later in our discussion of perceptions of ambivalence and the implications of our findings. 


\section{Case 2: Plurilingual Practices in Comparative Literature 120}

Comparative Literature 120 was a small first-year undergraduate course with 15 students, co-taught by two instructors. A total of 12 of the 15 students in the class were plurilingual. A key feature of the course was that plurilingualism-inspired pedagogy was proactively incorporated into the class activities; as a result, in the classes, students produced translingual spoken and written texts, and engaged in language awareness activities in the process of making literary comparisons. The research assistant carried out 7 observations of the 3-hr classes as both participant and nonparticipant observer. Data collected included field notes, recordings of students carrying out tasks in groups, and excerpts from interviews with students who accepted the invitation to be interviewed.

As part of the plurilingualism-inspired comparative focus of the course, students took part in activities that involved comparing literature from different cultures around the world. A traditional approach for such a course might be for students to read texts in translation and to attend lectures where they take notes or seminars in which they discuss what they have read, looking for theoretical, thematic, and comparative angles in the process. However, as a result of the incorporation of plurilingualism-inspired pedagogical approaches into this course, students were encouraged to take the initiative and present texts in groups or to the whole class in their original language, which other students may or may not understand. This approach involved certain students acting as plurilingual mediators, translating and explaining meanings and concepts to others who did not speak the language of presentation. The pedagogical aim was, thus, to stimulate comparative analysis of different aspects of the various texts presented. During class activities, the research assistant took notes, which she typed up retrospectively later in the day.

In one class activity, two students read a Chinese poem by Wang Wei (ca. 700-761), one in Cantonese and one in Mandarin. The following text shows the field notes taken by the research assistant during the poetry readings with names covered to guarantee confidentiality of the participants. 


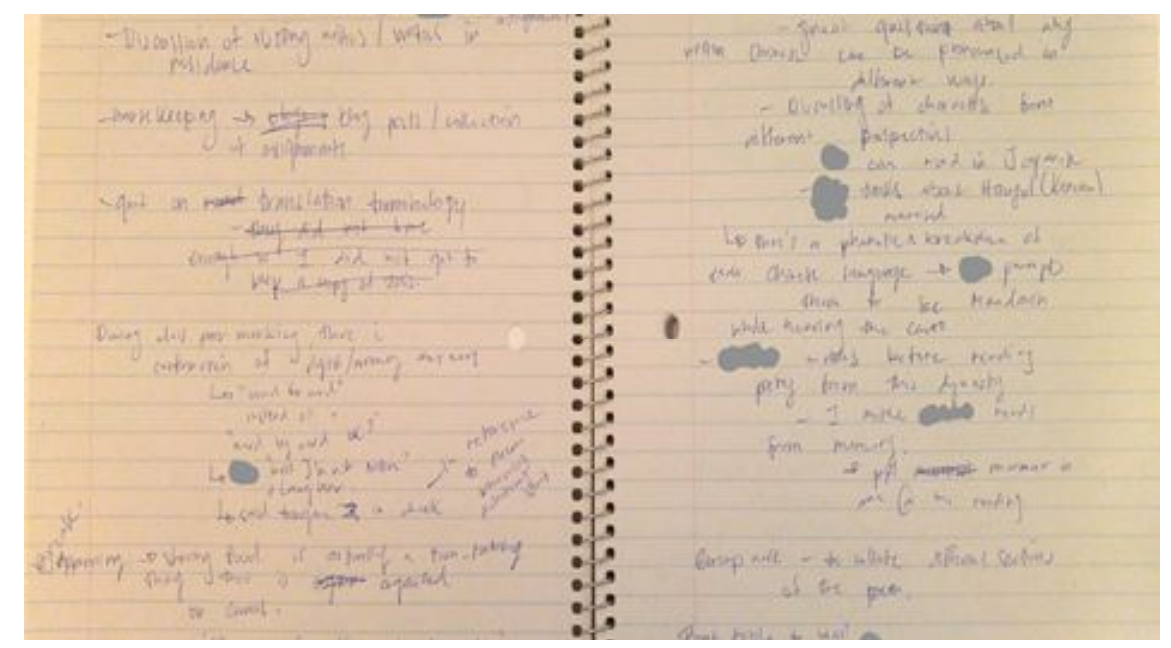

Figure 2: Handwritten Field Note.

As part of the initial data analysis process, the research assistant typed up the handwritten field notes later in the day, adding a few interpretive extras, as illustrated in the text below:

\footnotetext{
Before the class starts on the group work, two students read the poems aloud in class. $Y$ reads it aloud in Cantonese and $\mathrm{M}$ in Mandarin. $\mathrm{Z}$ asks why Chinese can be pronounced in different ways through the same written text. This leads to a great serendipitous conversation about Chinese characters and the relationship between different Chinese languages but also the influences the Chinese and the Chinese language has had on other Asian countries. 1-0 talks about how she can read the text in Japanese a little and K mentions Hangul (Korean.) There are pinyin versions in the text as well. $1-0$ prompts the class to look at the Cantonese break-down while listening to the Mandarin to hear/see the difference. Before $M$ reads it in Mandarin, he mentions how there are rules regarding how Wang Wei is read in China. (He has studied the poems while in elementary school; later he mentions how he has had to memorize a lot of these poems as part of the Chinese curriculum.) I notice that he doesn't even read the poem. He recites it from memory. I notice how people murmur in awe after he finishes. It's great how the students are able to showcase, not only their other languages, but their other ways of learning are being honoured.
}

Figure 3: Typed Notes.

One of the main challenges of plurilingual pedagogical approaches is to ensure that learning takes place, students are stimulated, their languages and identities recognized, and goals achieved. In the field notes above, the impacts of the plurilingual approach employed for the poetry readings are evident. First, the activity led to $\mathrm{Z}$ asking why Chinese can be pronounced in different ways through the same text, followed by a discussion that raised awareness of the features of the language of a group of students in the class. In terms of the effects of the activity, the research assistant notes in Figure 2: I notice how people murmur in awe after he finishes. These two results can be seen as successful pedagogy in that awareness is raised and interest stimulated in the process of comparing literature from different cultures, much more so, one would imagine, than if the students had been taking notes from a traditional lecture delivered by one of the instructors. In this sense, the activ- 
ity succeeded in successfully applying the following aspects of plurilingual pedagogy: opening up spaces for other languages and cultures in the classroom, promoting language awareness, and recognizing other languages and cultures as assets for learning rather than considering them to be hindrances.

\section{Plurilingual Students: Languages, Problems, and Strategies}

It would be an oversimplification, nonetheless, to laud the merits of plurilingual pedagogies based on two selected examples from courses, in a very multicultural university, and in courses where there was a strong connection between disciplinary "content" and language. After all, language is the content in linguistics and comparative literature, so the potential fit for plurilingual approaches may be strong. But what about in other contexts where content knowledge may be scientific and technical, with little relation to the language that drives plurilingual approaches? Moreover, what problems can emerge with students' use of languages other than English in class? Who is included and who is excluded? Is it beneficial for all students who speak and write English as an additional language to be using their first language rather than English in class? Should students with limited fluency in English not try to immerse themselves more in English so as to increase fluency and competence? And to what extent can plurilingual approaches succeed and become normal in institutions characterized by pervasive discourses that view plurilingual students through monolingual(ist) lenses, and in contexts where the hegemonic position of academic English is rarely challenged?

While it is beyond our scope to answer all of these questions, they merit consideration. Accordingly, the apparent success of the two examples illustrated above needs to be framed within broader questions and institutional contexts. In the following sections, therefore, selected interview data are presented to address the broader position of plurilingualism-inspired pedagogical approaches in universities such as WMU, where academic English dominates.

\section{Use of English at WMU}

During interviews, which were conducted in English, participants from both courses were asked how they used their different languages at the university. The responses below of Dai, Rou, and Shan show the dominance of English in their communication strategies:

Dai: The common language we have is English and we use it as a lingua franca. If we meet someone who do not speak Mandarin and they speak Cantonese and also so many CBC [Canadian-born Chinese]. They can speak English and Cantonese. They don't speak Mandarin, so we speak English to them. 
Rou: Guess I will speak my first language, Mandarin, to friends because my friends are almost from China. And for other classmates I will use English. I always use English also for the instructors. That's our common language.

Shan: So when I discuss problems with my classmates who are Chinese, we prefer to use Mandarin. But when I talk to people from other countries, we just use English.

Together, the responses above show that participants use Mandarin with fellow speakers and English with everyone else. Dai describes English as a lingua franca at the university and explains how he uses English with Chinese students who do not speak Mandarin, for example, Canadian-born Chinese " $\mathrm{CBC}$ " students. His response implies that he uses Mandarin otherwise with Chinese students. Rou and Shan also describe using Mandarin with fellow Mandarin speakers who are classmates and friends, and English with others, or as stated by Shan, "people from other countries."

Of interest here is the link that emerges from these three participants not only in terms of the institutional position of English at the university, but also between the idea of one language and one country: Mandarin for people from China and English for students of Chinese ethnicity who speak Cantonese and/or were born in Canada. In effect, these participants appear to be framing their use of language within the constraints of the university around rather static views of language and nationhood that fail to reflect the fluid transnational nature of language and nationhood of many of the students and of the city in which they live. For example, such assertions imply that Canadian-born Chinese students are by nature Cantonese speakers while, in fact, some may speak Mandarin and/or other Chinese dialects, or may have learned Mandarin in heritage language schools, but may lack confidence or fluency to speak it with fluent Mandarin speakers.

Another factor complicates this view of Mandarin as a lingua franca as a norm or language-identity choice among fellow Mandarin-speaking students. As stated in the following excerpts from interview with Dai and Shan, Mandarin is also used not only strategically as a learning strategy but also as a protective shield against communication problems that may come up in classes that require interactions in advanced academic English:

Dai: In the classroom, we still need to discuss with each other in small groups. Sometimes you need to rephrase your ideas or what you are saying several times to make yourself understood.

Interviewer: Yeah, when you speak English.

Zhang: Yeah. Sometimes I feel really shameful. They cannot understand me. 
Shan: For example, when I am in a group with 3 or 4 people that they all don't speak Chinese, I will feel stress. Since a lot of people use English as their first language and they are using it very fluently, so sometimes I feel I just can't catch up with them. I can't communicate with them very well. But when I am in a group with some Chinese students, I will feel comfortable and confident.

The use of languages such as Mandarin in class, therefore, is a strategic learning strategy for some students, as seen above; however, in the cases of Dai, Rou, and Shan, such usage is also described as a coping strategy as they seek out fellow Mandarin speakers to avoid the stresses and embarrassment of not speaking and/or understanding English-speaking classmates.

\section{Other Challenges and Strategies}

Not understanding English-speaking peers and lacking the confidence to discuss topics with them, as described above, were among several challenges that participants described facing at the university. Chris described problems that speaking more than one language brings in terms of translation and logic:

Chris: I think being plurilingual is quite, ah, I'm not sure, like how to say that. But like, it's very stressful.

Interviewer: It's stressful?

Chris: Yeah, 'cause, ah, your brain process everything in your first language, right?

Interviewer: Okay.

Chris: But then when, if I was to manipulate it in different language, the logic kinda mixed up and doesn't work very well. I find it's really hard to process everything in Chinese, then write out in English, 'cause my efficiency in Chinese is much greater than English. I can, like, write very beautiful sentences in Chinese but not so much in English.

Chris's sentiment was echoed by Wei:

Wei: Yeah. But since I have already been in Canada for three years, so I think I'm getting more familiar with English and sometimes the logic of English also affects my logic in Chinese. It seems hard for me to write some Chinese essays now.

According to Chris and Wei, understanding the problems that some plurilingual students face goes beyond mere competence in English. It also relates to cognitive factors such as conceptualizing knowledge in one lan- 
guage, translating it into another linguistically and through writing, and navigating the different means of ordering ideas logically through translation.

In interviews, participants were also asked to describe the strategies that they used to overcome challenges and difficulties. Shui described working in Mandarin-speaking study groups for assignments; Rou also described working in study groups for assignments (without specifying the languages used) and working alone for exam preparation:

Shui: My friends and I, sometimes when the teacher release an assignment, we will work together and we discuss in Mandarin. This will be quicker and improve our accuracy, yeah, to do each question.

Rou: I like to review the lesson by myself. I don't like to join study group for exams but for assignment, I prefer to join study group to solve problems. But for exams, I like to do review by myself.

One strategy that students may opt for, but which they tend not to want to discuss, is hiring a private tutor. Rou was the only participant who brought up private tutors in his interview:

Rou: Oh, yeah. I paid for a tutor the first year when I came to Canada, for the first semester I took linguistic course. And I have no idea about the course. I am not good at English speaking or writing or listening at that time. For the first exam I got a very low grade so I'm looking for the tutor to help me with the course. I think it was very helpful. Finally I got a very high grade that semester. The tutor told me what linguistics is and what this course is about and how to solve problems. Actually he just translates what the professor says because he [the tutor] is in my class and he understands my language [Mandarin].

To sum up this section, English (in particular, academic English) and Mandarin are both seen ambivalently as contextually sensitive problems and solutions. English is a problem when it becomes a barrier based on lack of competence or confidence; Mandarin is a perceived as a problem when knowledge needs to be translated from Mandarin to English along with the rhetorical conventions that each written form of the language requires. Nonetheless, Mandarin is also a solution, a strategy for learning, and in some cases a coping strategy for students who lack confidence to communicate with native speakers of English. English is by default the aspired to (but not always attainable) solution: the language through which students must communicate knowledge effectively to pass courses in different modes of assessment.

Herein lies the ambivalence that plurilingual students often negotiate between English and their other languages in higher education settings, an ambivalence that is not only personal and idiosyncratic, but also discursively 
constructed by social and institutional discourses around multi/plurilingualism in higher education settings.

\section{Ambivalence: Plurilingualism in an English-Dominant University}

WMU, an English-dominant multicultural institution, could be characterized as one that presents a public face of being proud of its global outlook, internationalization, and multiculturalism; nonetheless, across the university in the different learning contexts, an accompanying discourse prevails, that of multilingual classrooms framed pedagogically by the lenses of monolingual English. This ambivalence was evident in the interview responses of Amber, a Korean student, to questions about the multilingual nature of the university.

Amber: if you talk to people, they wouldn't, I guess it'd be weird if you just all of a sudden, spoke to them in a foreign language and you expect them to speak the same, right? You would normally approach them in English and that's just well-recognized. That's the norm, right? Essentially, I don't feel like it's a multilingual environment. But, like, academically, you know, students-speaking, I know WMU is multilingual. Like, make sure that everyone knows that this is a setting of multilingualism, celebrating multiculturalism, and such. I think it's just difficult to break out of that too, since, well, because of that English-only ideology as well as, the whole, the English being the, like, the language that's being taught, right?

In response to an interview question asking her about multilingualism at WMU, Amber provides an illustration of the complexity and ambivalence that characterizes perceptions of multi/plurilingualism at WMU. She begins by stating her understanding that the norm at the university is to begin by addressing people in English and for interactions to continue in English, rather than in a foreign language, which would be "weird." Ambivalence creeps into her response when she states that, in essence, she does not feel like WMU is multilingual, and then stating that academically and in terms of students speaking, the university is multilingual, and that it presents a public face of making everyone know that it is a setting of multilingualism where multiculturalism is celebrated. She ends by highlighting the role of English as the medium of instruction as the key factor in a pervasive English-only ideology at the university.

Within the ambivalence of a multilingual, English-dominant university, most participants in the study had little doubt that competence in English gives students an added advantage, as illustrated in the excerpts below from interviews with Meghan and Chris: 
Meghan: Yeah, I think that being English-dominant, native-English speaker, whatever you wanna call it, ah, is an advantage at WMU. Simply because, even though we're a multicultural environment, all of our learning is done in English. And, when you're getting into, some, like, kinda like, hardcore literary theories, that are like way off the wall and difficult to understand on their own, like, that's hard enough to begin with. But at least knowing the language and having a handle on, kinda the fine-tuned details and the subtleties of the English language, I definitely think that gives me an advantage over someone who may be struggling with that.

Chris: I think English is a still a quite difficult barrier for most of Chinese students. I guess, just find not many Chinese people take literature or English courses. People would rather, ah, work with the mathematics, ah, instead of trying to learn English. 'Cause when I took chemistry, the professor didn't really look at grammars or everything. They just look at, like, how you come back to lab, whether you learn from the lab. I think that's why most Chinese students don't improve a lot through these courses. So I highly suggest them taking, like, more arts-related courses.

In the excerpts above, Meghan and Chris present a view of competence in English as both an advantage and a barrier. Meghan links the advantage of being English-dominant to the fact that English is the medium of instruction at the university, in spite of its multiculturalism, especially when it comes to engaging with and understanding complex theories such as the "hard core literary theories" that she studies on her course. For the same reason, perhaps, Chris states that fewer Chinese students take literature or English courses. At the same time, he suggests that more of his fellow Chinese students should take arts courses, presumably because they will improve their English more than in courses such as chemistry, where professors do not check their grammar.

Together, the excerpts above illustrate some of the complexity associated with the ambivalence surrounding multi/plurilingualism at WMU. Amber states that the university does not feel multilingual before saying "I know WMU is multilingual"; both Amber and Meghan highlight the conceptual paradox of being in a multilingual environment while learning is through English; Meghan and Chris view the demands of studying in language-rich courses such as literature and arts and the position of English competence therein from different perspectives: as an advantage for Meghan and a barrier for Chris and other Chinese students. 


\section{Concluding Remarks and Implications}

Through presenting selected data from a 1-year study of plurilingualism as an asset across the disciplines in Canadian higher education, we have shown two examples of courses where students were able to successfully make use of their plurilingual resources in the process of engaging with course content. We then presented selected interview data in which participants explained how and why they use different languages, revealing the broader contextual complexities surrounding the use of languages other than English in classes at the university. We suggested that the tension between a plurilingual learning process and a monolingual assessment product lay at the heart of a sense of ambivalence surrounding students' practices. This ambivalence was seen to be embedded within the university's structures, thus increasing its central role in its discursive reproduction by students. In this sense, it may be more likely that plurilingual students are structurally conditioned by these ambivalent discourses and that they internalize and reproduce them (Archer, 2003).

In terms of employing plurilingualism as a lens though which we view our participants' practices, our findings highlighted a number of key factors. First, it is evident from the findings that the plurilingual students we studied are socially situated actors (Moore \& Gajo, 2009), and that their practices were dependent on context and could change according to the opportunity or constraint of the specific social/educational context (Coste, Moore, \& Zarate, 1997, 2009; Lüdi \& Py, 2009). Moreover, in contexts where plurilingual pedagogy was actively integrated in the course (Comparative Literature 220) or in which an instructor opened up spaces for students to use languages other than English as tools for learning (Linguistics 300), students' selfesteem, agency, and self-efficacy (Piccardo, 2013) appear to have been enriched. As part of this process, plurilingual mediators were involved in the negotiation of the meaning of written texts and mediation of the cognitive processes involved while carrying out specific tasks.

Our first research question asked how and why plurilingual university students use languages other than English in the process of learning course content. Our findings from classroom recordings showed that students used Mandarin to present and engage with course content, including technical academic concepts in "pluri-friendly" classes. In interviews, participants described using Mandarin with other Chinese students who spoke Mandarin and using English with others. The reasons interviewees gave for using Mandarin rather than English ranged from feeling more comfortable to fear of embarrassment in front of native speakers of English.

Our second question asked whether the use of languages other than English enriches learning. Our data suggest that the use of Mandarin, as recorded in in-class interactions and described in interviews, played a role in enriching learning through making students more self-confident and allowing them to make the most of the linguistic repertoires to analyze complex academic 
content. This was the case even though, in some cases, participants described having problems translating knowledge and rhetorical norms from Mandarin to written academic English.

Finally, we asked what the pedagogical implications were of encouraging students to engage in plurilingual practices in different disciplinary contexts. We begin by suggesting that in the contexts of arts and humanities courses where language and cross-cultural analysis are related to course content, students' other languages and cultural perspectives provide rich tools for learning. As part of any attempt to encourage the use of languages such as Mandarin in linguistically diverse classes, as illustrated above, plurilingual mediators are essential - plurilingual students and/or teaching assistants can play mediation roles.

In terms of extending our optimistic conclusion to other disciplines, where there is a less evident connection between "language and content," for example, natural and applied sciences, applying plurilingualism-inspired approaches may be more problematic (see Marshall \& Walsh Marr, 2018, for a discussion of instructors' responses to linguistically diverse, writing-intensive classes across the disciplines). Where instructors self-identify as experts in disciplinary content knowledge rather than language, the scope for plurilingual pedagogies changes. Nonetheless, we would argue that even in such classes, measures such as permitting students to study in language-specific groups (where appropriate and possible) and employing plurilingual teaching assistants to act as mediators with different language groups are good starting points that will serve to enhance the learning of discipline-specific content. Given that a large number of plurilingual students are international students paying triple or even quadruple tuition to attend our Canadian universities, we suggest that there is a moral obligation for institutions to consider all ways to help all their students to succeed, including learning through languages other than English in English-dominant institutions.

\section{Note}

1. See Marshall and Moore (2018) for a discussion of how plurilingualism differs from other terms such as bi/multilingualism.

\section{Acknowledgement}

Funding for this project was provided by a Simon Fraser University (SFU) VPR Social Sciences and Humanities Research Council (SSHRC) Bridging Grant.

\section{The Authors}

Steve Marshall is an associate professor in the Faculty of Education at SFU. He researches academic literacy and plurilingualism in Canadian higher education. 
Danièle Moore is a university professor in educational sociolinguistics at the Faculty of Education, SFU, Canada, and a research director at the Sorbonne University, France. Her research interests include issues related to language policies, bi/plurilingualism, curriculum development, and teacher training in multicultural contexts.

Connie Lam James is a doctoral student in the Languages, Cultures and Literacies Program at SFU. She works with international and multilingual students in secondary and higher education.

Xiaojie Ning is a doctoral student in the Languages, Cultures and Literacies Program at SFU. She is researching the experiences of ethnic minority students who are studying English in Chinese higher education.

Pedro dos Santos is a doctoral student in the Languages, Cultures and Literacies Program at SFU and a lecturer of Portuguese at the University of British Columbia. He is interested in academic literacy of bi/plurilingual students in higher education and plurilingual pedagogies.

\section{References}

Archer, M. S. (2003). Structure, agency and the internal conversation. Cambridge: Cambridge University Press.

Berthoud, A. C., Grin, F., \& Lüdi, G. (Eds.). (2012). Exploring the dynamics of multilingualism: The DYLAN project. Amsterdam: John Benjamins.

Bourdieu, P. (1994). Language and symbolic power. Cambridge, MA: Harvard University Press.

Canagarajah, S., \& Liynage, I. (2012). Lessons from pre-colonial multilingualism. In M. MartinJones, A. Blackledge, \& A. Creese (Eds.), The Routledge handbook of multilingualism (pp. 49-65). London/New York: Routledge.

Chen, L. (2018). The enactment of academic language policy in the international university: A mixedmethods investigation. (Doctoral dissertation, Western University, Canada).

Corcoran, J., Gagné, A., \& McIntosh, M. A conversation about "editing" plurilingual scholars' thesis writing. Canadian Journal for Studies in Discourse and Writing/Rédactologie, 28, 1-25.

Coste, D., Moore, D., \& Zarate, G. (1997). Compétence plurilingue et pluriculturelle. Strasbourg: Éditions du Conseil de l'Europe.

Coste, D., Moore, D., \& Zarate, G. (2009). Plurilingual and pluricultural competence. Strasbourg: Council of Europe. Council for Cultural Co-operation. Education Committee.

Council of Europe. Council for Cultural Co-operation. Education Committee. Modern Languages Division. (2001). Common European framework of reference for languages: Learning, teaching, assessment. Cambridge University Press.

Council of Europe. (2018). Common European framework of reference for languages: Learning, teaching, assessment. Companion volume with new descriptors.

Englander, K., \& Corcoran, J. N. (2019). English for research publication purposes: Critical plurilingual pedagogies. Routledge.

Galante, A. (2018). Plurilingual or monolingual? A mixed methods study investigating plurilingual instruction in an EAP program at a Canadian university (Doctoral dissertation, University of Toronto, Canada).

Galante, A. (2019). “The moment I realized I am plurilingual”: Plurilingual tasks for creative representations in EAP at a Canadian university. Applied Linguistics Review.

Lau, S., \& Van Viegen, S. (Eds.). (forthcoming). Plurilingual pedagogies: Critical and creative endeavors for equitable language (in) education. New York, NY: Springer International Publishing.

Liddicoat, A. J. (2014). Pragmatics and intercultural mediation in intercultural language learning. Intercultural Pragmatics, 11(2), 259-277.

Lin, A. (2013). Toward paradigmatic change in TESOL methodologies: Building plurilingual pedagogies from the ground up. TESOL Quarterly, 47(3), 521-545.

Lüdi, G., \& Py, B. (2009). To be or not to be . . a plurilingual speaker. International Journal of Multilingualism, 6(2),154-167. 
Marshall, S. (in press). Applying plurilingual pedagogy in first-year Canadian higher education: From generic to scientific academic literacy. In S. Lau \& S. Van Viegen (eds.). Plurilingual pedagogies: Critical and creative endeavors for equitable language (in) education. New York, NY: Springer International Publishing.

Marshall, S., \& Moore, D. (2013). 2B or not 2B plurilingual? Navigating languages literacies, and plurilingual competence in postsecondary education in Canada. TESOL Quarterly, 47(3), 472-499.

Marshall, S., \& Moore, D. (2018). Plurilingualism amid the panoply of lingualisms: Addressing critiques and misconceptions in education. International Journal of Multilingualism, 15(1), 19-34.

Marshall, S., \& Walsh Marr, J. (2018). Teaching multilingual learners in Canadian writing-intensive classrooms: Pedagogy, binaries, and conflicting identities. Journal of Second Language Writing, 40, 32-43.

Moore, D., \& Castellotti, V. (Eds.). (2008). La compétence plurilingue: Regards francophones (Vol. 23). Peter Lang.

Moore, D., \& Gajo, L. (2009). Introduction-French voices on plurilingualism and pluriculturalism: Theory, significance and perspectives. International Journal of Multilingualism, 6(2), 137-153.

Piccardo, E. (2012). Médiation et apprentissage des langues : Pourquoi est-il temps de réfléchir à cette notion? ELA : Études de Linguistique Appliquée, 167, 285-297.

Piccardo, E. (2013). Plurilingualism and curriculum design: Toward a synergic vision. TESOL Quarterly, 47(3), 600-614.

Piccardo, E., \& North, B. (in press). The dynamic nature of plurilingualism: Creating and validating CEFR descriptors for mediation, plurilingualism and pluricultural competence. In S. Lau \& S. Van Viegen (eds.). Plurilingual pedagogies: Critical and creative endeavors for equitable language (in) education. New York, NY: Springer International Publishing.

Statistics Canada. (2011). 2011 Census of population: Linguistic characteristics of Canadians. Retrieved from http://www.statcan.gc.ca/daily-quotidien/121024/dq121024a-eng.htm

Statistics Canada. (2016). Census profile, 2016 Census. Available at http://www12.statcan.gc.ca/ census-recensement/2016/dp-pd/prof/details/page.cfm?Lang=E\&Geo1=CMACA\&Code1=9 $33 \&$ Geo2=PR\&Code2 $=59 \&$ Data $=$ Count\&SearchText=Vancouver\&SearchType=Begins\&Sear chPR $=01 \&$ TABID $=1 \& B 1=$ All

Van Viegen, S., \& Zappa-Hollman, S. (forthcoming). Plurilingual pedagogies at post-secondary level: Possibilities for intentional engagement with students' diverse linguistic repertoires. Language, Culture and Communication.

Zarate, G. (2004). Cultural mediation in language learning and teaching. Council of Europe. 